\title{
ESTUDO DAS MANIFESTAÇÕES PATOLÓGICAS NO RESERVATÓRIO ELEVADO DO IFAL CAMPUS PALMEIRA DOS ÍNDIOS
}

\author{
DÁRIO A. B. \\ Discente Engenharia Civil \\ Instituto Federal de Alagoas \\ Alagoas; Brasil \\ darioanjos10@gmail.com
}

\author{
RICARDO C. S. \\ Engenheiro Civil \\ Instituto Federal de Alagoas \\ Alagoas; Brasil \\ ricardo.soares@ifal.edu.br
}

\begin{abstract}
RESUMO
O reservatório elevado de uma região é uma construção destinada a receber água e abastecer todas as edificações de referência da localidade. Outra função importante é garantir este abastecimento com pressão apropriada, a qual é obtida por diferença de nível. Este trabalho apresenta uma análise sobre as manifestações patológicas do reservatório de concreto armado, localizado no Instituto Federal de Alagoas, Campus Palmeira dos Índios, no Agreste de Alagoas. Um levantamento topográfico identificou um recalque deste reservatório e visitas realizadas in loco identificaram patologias mais típicas da região. O presente trabalho detalha as manifestações patológicas identificadas no objeto de estudo, relatando causas e descrevendo formas de recuperação e prevençao das patologias identificadas, tendo como referência literaturas apropriadas e atualizadas a partir do ano de 2010.
\end{abstract}

Palavras-chave: concreto armado, patologia das construções, reservatórios.

\section{ABSTRACT}

The elevated reservoir of a region is a construction intended to receive water and supply all the reference buildings of the locality. Another important function is to ensure this supply with proper pressure, which is obtained by level difference. This paper presents an analysis of the pathological manifestations of the reinforced concrete reservoir located at the Federal Institute of Alagoas, in Palmeira dos Índios, in the Wild of Alagoas. A topographic survey identified a repression of this reservoir and visits made on site identified more typical pathologies of the region. This paper details the pathological manifestations identified in the object of study, reporting causes and describing ways of recovery and prevention of the identified pathologies, having as reference appropriate and updated literature from the year 2010.

Palavras-chave: reinforced concrete, buildings pathogolia, reservoirs.

\section{INTRODUÇÃO}

Os reservatórios elevados são unidades hidráulicas de acumulação e distribuição de água, que ficam sistuados em pontos estratégicos do sistema. Estes são normalmente localizados nas regiões de cota topográficas mais altas, e num nível elevado em relação ao terreno. Por esse motivo, o reservatório elevado condiciona e equaliza as pressões de água para o abastecimento adequado da região referente. Além de atenderem às diversas finalidades, são elementos visiveis e de maior destaque no sistema de distribuição de água (TSUTUYA, 2006).

O sistema mais utilizado para construção dos reservatórios é por meio de elementos de estruturas de concreto armado, por ser muito resistente e por possibilitar a variedade de forma. Nos elementos estruturais, como pilar, viga e laje, devese ter uma maior cautela, quanto a manisfestações patológicas, pois são as partes da construção que suportam e sustentam as cargas provenientes no reservatório.

Os reservatórios elevados estão sempre expostos a ação da água. A exposição à água da chuva, à umidade proveniente do solo e aquela proveniente do uso da edificação habitacional, devem ser consideradas em projeto, pois a umidade acelera 
os mecanismos de deterioração e acarreta a perda das condições de habitabilidade e de higiene do ambiente construído (NBR 15575-1, 2013). Desse modo, a ação da água proveniente de diferentes situações podem acarretar ou aumentar o desenvolvimento de patologias.

O termo patologia, segundo os dicionários, é a parte da Medicina que estuda as doenças. As edificações também podem apresentar defeitos comparáveis a doenças: rachaduras, manchas, descolamentos, deformações, rupturas, etc. Por isso, é convencional chamar o estudo sistemático desses defeitos de Patologia das Construções (VERÇOZA, 1991).

A patologia na construção civil ainda pode ser definada como a redução do desempenho de uma estrutura quanto à estabilidade, estética e, principalmente, durabilidade da mesma com relação às condições a que está submetida (RIPPER et al., 1998). A norma NBR 15575-1 (ABNT, 2013) define desempenho como o "comportamento em uso de uma edificação e de seus sistemas."

A perda de desempenho devido a patologia na cosntrução pode ocorrer por diversos motidos, dos quais se destacam, de acordo com Rodrigues (2013): projetos mal detalhados, falta de critérios durante a execução do serviço, baixa qualidade e emprego inadequado dos materiais aplicados, manutenção inadequada do edifício, agentes de degradação que atuam na edificação com o decorrer do tempo, métodos construtivos. Estes fenomenos causam sintomas resultantes de falhas em alguma das etapas do sistema construtivo da edificação e mecanismos de degradação, tais sintomas são as manifestações patológicas.

Como a manifestação patológica pode ser influenciada pelo comportamento da estrutura em uso, pelo tempo e pelas condições de exposição, nota-se, desta maneira, que existe uma forte relação entre a manifestação patológica e desempenho, vida útil e durabilidade da edificação (ANDRADE; SILVA. 2005).

$\mathrm{Na}$ época atual, o estudo das manifestações patológicas na construção civil intensificam cada vez mais, em função do fato de que até há pouco tempo imaginava-se que as estruturas de concreto durariam infinitamente, mas, estudo comprovaram que isto não é verdadeiro (MATTJE, 2003).

O entendimento das causas que provocam as patologias nas edificações e a percepção de que medidas preventivas na fase de projeto e cuidados na execução representam uma gama de economia em relação às recuperações e raparos.

As patologias apontadas por Pereira (2010), que ocorrem mais em estruturas de concreto armado, são: corrosão dos materiais; desplacamento do concreto armado por corrosão das armaduras; deficiente execeção da juntas verticais e horizontais nas fases de concretagem; tricas e fissuras do concreto armado; degradação dos revestimentos interiores e exteriores (impermeabilizantes, argamassa, pintura); degradação dos elementos metálicos do interior e exterior do reservatório; e problemas de fundações.

O recalque diferencial das fundações é uma das patologias mais complexa de se estudar, pois, segundo Alonso (1991), uma das carecterística das fundações é que as mesma ficam enterradas e, assim, é impossível inspecioná-las facilmente após sua conclusão, como ocorre em pilares, paredes, vigas e lajes, por exemplo.

A NBR 6122 (ABNT, 2019) define o recalque como sendo o movimento vertical descendente de um elemento estrutural. E define também o recalque diferencial específico como a relação entre diferenças dos recalques de dois apoios e a distância entre eles. Assim, o recalque em fundações acontece quando o contato entre fundação e solo se rompe, fazendo com que a fundação afunde mais do que projetado.

O termo recalque é usado em engenharia civil, de acordo com Milititsky (2005), para caracterizar o fenômeno que ocorre quando uma edificação sofre um rebaixamento devido ao adensamento do solo sob sua fundação. Quando uma parte da obra rebaixa mais que a outra, ocorre o recalque diferencial, que é uma das principais causas de fissuras em edificações, podendo até levar a obra à ruina. Por isso, é necessário ter um estudo adequado de patologia das construções.

O estudo sobre patologias é de grande importância, pois ao indentificá-las, descobre-se a causa e gênese do mesmo, possibilitando a solução do problema. Assim, a identificação da causa a partir de onde se desencadeia o problema na estrutura em concreto é indispensével de qualquer etapa de tratamento das manifestações patológicas. (GOMES; SANTOS. 2016). 
Dessa forma, o presente trabalho foi realizado com a finalidade de levantar as manifestações patológicas incidentes no reservatório elevado de água em concreto armado, localizado no Instituto Federal de Alagoas (IFAL), CAMPUS Palmeira dos Índios. E a partir disso, indentificar as causas, o diagnóstico ou tratamento e a prevenção das manifestações patológicas.

\section{METODOLOGIA}

A metodologia empregada neste estudo se baseou em vistorias realizadas in loco, com levantamento visual e fotográfico do reservatório estudado, para identificação de manifestações patológicas. Um levantamento topográfico também foi realizado para identificar possíveis recalques. Estas etapas de vistorias e levantamento geraram informações suficientes para identificar as possíveis causas e origens das manifestações patológicas, para diagnóstico e sugestões de reparos e prevenção destas, tendo como referência literaturas apropriadas e atualizadas a partir do ano de 2010.

Portanto, para atingir o objetivo do presente trabalho, foi realizada pesquisas bibliográficas, que procuram explicar um problema, as patologias construtivas, a partir do registro disponível, utilizando-se de referenciais teóricos já trabalhados e devidamente publicados por outros pesquisadores, conforme a metodologia citada por Severino (2007).

\section{RESULTADOS E DISCUSSÕES}

Com base na metodologia mostrada, os resultados foram apresentados em duas partes: levantamento das manifestações patológicas e anélise dos dados para sugerir possíveis reparos e prevenções.

\subsection{Levantamento das manifestações patológicas}

A primeira parte do diagnóstico consiste em identificar as manifestações patológicas, a partir de levantamento visual e fotográfico feito no reservatório elevado do IFAL, mostrado na Figura 1.

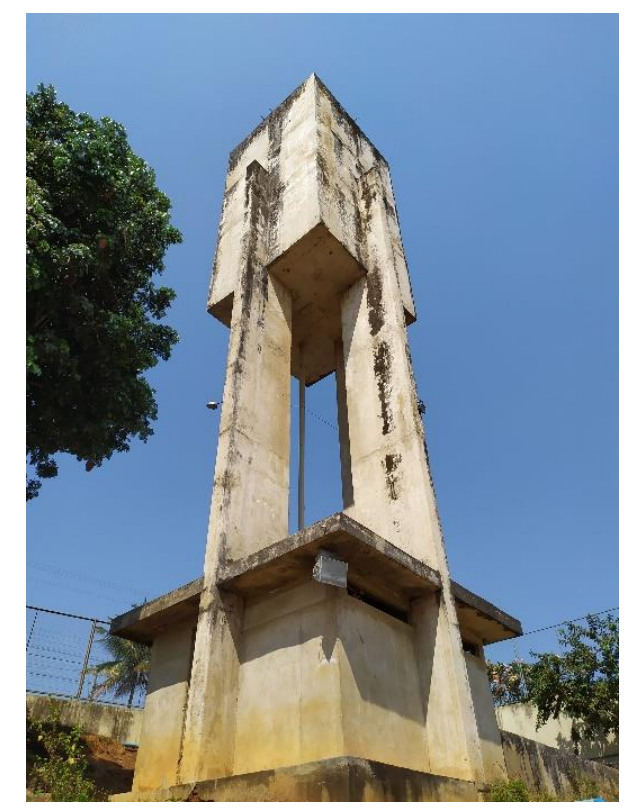

Figura 1: Reservatório analisado

Nessa estrutura observou-se a existências de manchas e sujidades nas fachadas, conforme a Figura 2. De acordo com Carrió (2010), sujidade pode ser definida como a acumulação e permanencia de partículas sujas nas fachadas das edificações, seja em sua superficie exterior, seja no interior de poros superficiais. Sendo identificadas por sua coloração mais escura. As causas deste tipo de patologia são a falta de manutenção e conservação do reservatório, e a ação da chuva nas partes expostas da estrutura. A falta de pingadeiras, que agora é necessário segundo a NBR 15575-1, contribui para o aparecimento destas patologias. O crescimento das manchas está diretamente ligado à existencia de umidade. 


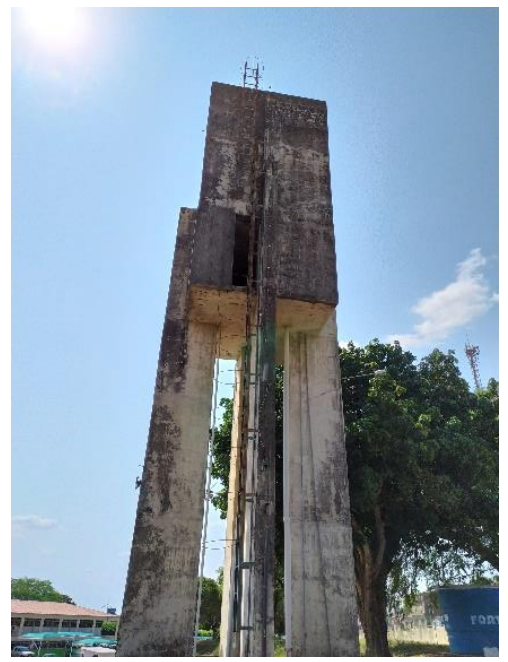

(a)

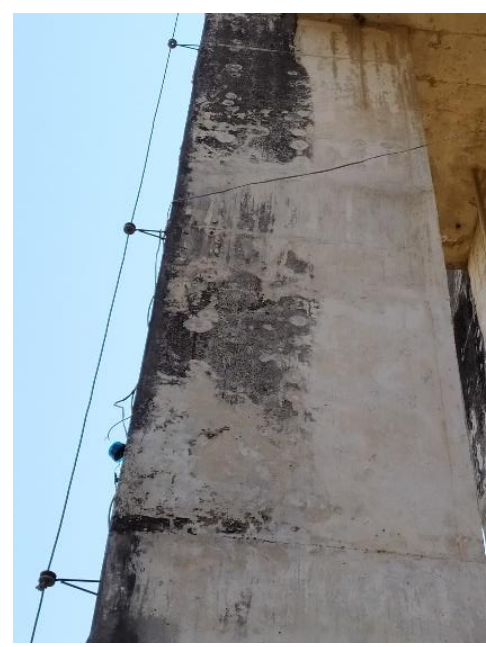

(b)

Figura 2: Manchas e sujidades: (a) fachada; (b) pilares.

A Figura 3 mostra o registro das lajes, vigas e pilares. A figura apresenta um detalhe das vigas e lajes, tendo uma visão da parte inferior. Nota-se, que em todos esse elementos estruturais analisados, houve um processo de degradação avançado, sendo possível ver a fissura junto ao descolamento do cobrimento de concreto e exposição da armadura, que pode-se dizer está em processo corrosivo.

O cobrimento das armaduras é a garantia de proteção que deve ser levada em consideração no projeto e ser executado cuidadosamente, pois através da abertura de fissuras nos elementos estruturais do reservatório, onde os agentes agressivos do meio ambiente agem sobre o concreto e sobre a armadura, ocorre os processos de deterioração e corrosão, respectivamente (GUIMARÃES, 1995). O cobrimento segundo a NBR 6118 (ABNT, 2014), representa a medida entre a superfície externa da armadura e a face da concreto.

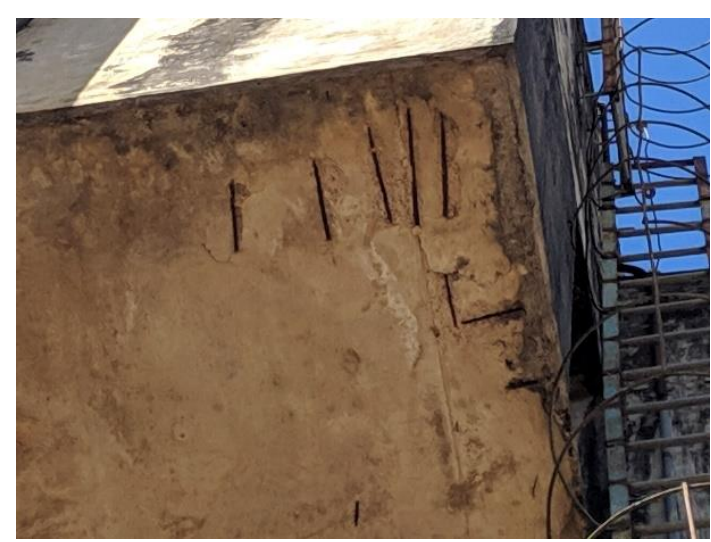

(a)

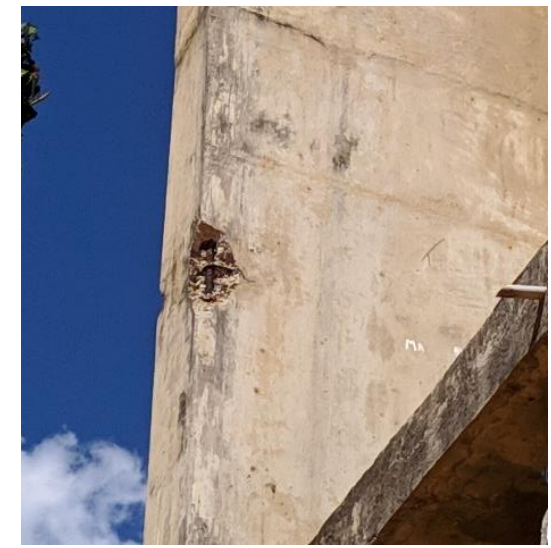

(b)

Figura 3: Manifestações patológicas - Fissuras com armadura exposta: (a) lajes e vigas; (b) pilares.

Foram registrados, ainda, fissuras que não causaram a exposição de armadura, conforme a Figura 4. Umas das causa prováveis é o subdimensionamento dos estribos, que ocasionam fissuras verticais, como mostrada na figura. A ocorrência desta patologia deveria ser evitada na fase de projeto, ao considerar o estados-limites de serviço. 


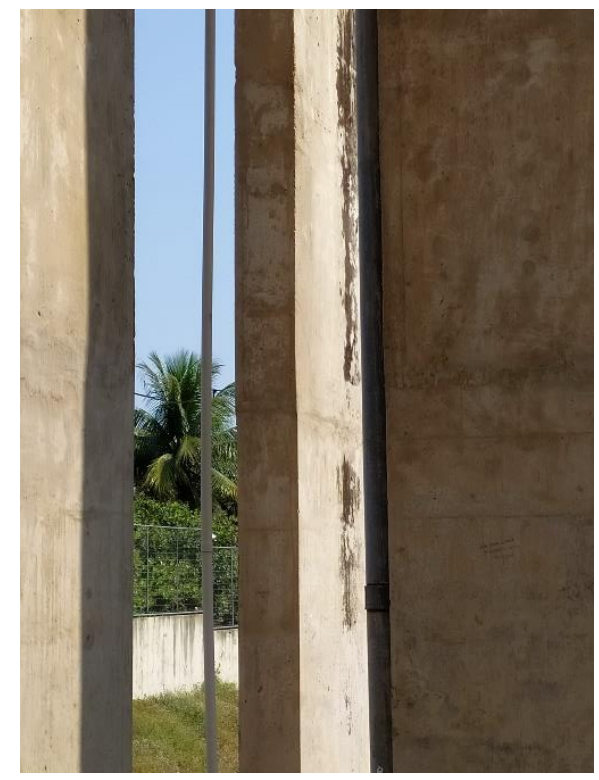

Figura 4: Fissuras sem exposição de armaduras

Por fim, o levantamento topográfico constatou um recalque diferencial nas fundações. Tal requalque pode ser ou vir a ser um dos maiores causadores de fissuras, trincas e rachaduras. A causa do recalque foi devido a escavação próxima ao reservatório, que modifica a distribuição de tensões da fundação.

\subsection{Análise das manifestações patológicas}

Para mostra o resultado obtido na análise do reservatório foi usada a Tabela 1, que mostra as manifestações encontradas como: sujidade, fissuras, corrosão de armadura exposta, apresentando as possíveis causas e sugerindo técnicas de reparo ou tratamento. A tabela mostra, também, a nacionalidade do autor das técnicas usadas para reparos. 
Tabela 1: Análise das manifestações patológicas identificadas no reservatório

\begin{tabular}{|c|c|c|c|}
\hline $\begin{array}{l}\text { Manifestação } \\
\text { patológica }\end{array}$ & Causas prováveis & Recuperação e Prevenção & País \\
\hline $\begin{array}{l}\text { Manchas e } \\
\text { sujidades }\end{array}$ & $\begin{array}{l}\text { Não possui pingadeiras } \\
\text { (contado da água da chuva); } \\
\text { Falta de manutenção }\end{array}$ & $\begin{array}{l}\text { Construção de pingadeiras; } \\
\text { Limpeza total das superfícies } \\
\text { expostas (CARRIÓ, 2010); } \\
\text { Realização de manutenção } \\
\text { periódica; Implementação de } \\
\text { texturas mais lisa e cores mais } \\
\text { escuras (CARRIÓ). }\end{array}$ & 2 \\
\hline $\begin{array}{l}\text { Fissuras e } \\
\text { rachaduras sem } \\
\text { armadura } \\
\text { exposta }\end{array}$ & $\begin{array}{l}\text { Falha de projeto: estribos } \\
\text { subdimensionados; }\end{array}$ & $\begin{array}{l}\text { Realizar furos ao longo das } \\
\text { fissuras; aplicação do selante } \\
\text { externo; colocar tubos de injeção } \\
\text { ao longo da fissura; introduzir } \\
\text { epóxi com baixa viscosidade. } \\
\text { (CÁNOVAS, 1998) }\end{array}$ & 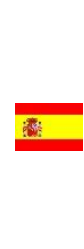 \\
\hline
\end{tabular}

Escoramento da estrutura;

Remoção do concreto danificado;

Limpeza rigorosa do aço;

Avaliação da perda de aço

(necessidade de reforço);

Fissuras, Falha de projeto: cobrimento desagregações e da armadura abaixo da mínima armaduras de norma; Falha de execução: expostas com corrosão não utilização de espaçadores para garantir o cobrimento.
Tratamento ante corrosivo na armadura; Aplicação de produto com função de aderência; Aplicação de graute para reparos; Lançamento do concreto (tempo de cura adequada); Pintura de acabamento; Respeitar cobrimento nominal de norma; (TORRES et al., 2015)
Escavação nas proximidades, não previsto em projeto.

Realizar injeção de argamassas abaixo da fundação, conforme CAPUTO (2012).

\footnotetext{
Recalque

diferencial na fundação
}

\section{Fonte: Autores, 2019}

O método de injeção de argamassa (CAPUTO, 2012), para reparo de recalque diferencial na fundação, foi escolhido porque as injeções se propõem a melhorar as características dos maciços terrosos, melhorando a resistência e a impermeabilização.

A partir das vistorias do local em que se encontra o reservatório, foi observado que o cobrimento executado era muito pequeno. $\mathrm{O}$ reservatório tem cerca de 25 anos, no período de sua construção a norma vigente para cobrimento nominal mínimo era a NBR 6118 (ABNT, 1980). O cobrimento nominal, hoje em dia, como mostrado na NBR 6118 (ABNT, 2014), aumentou em relação à época em que o reservatório foi construído. A Tabela 2 mostra este acontecimento para classe de agressividade ambiental II.

Mesmo o cobrimento nominal de época da construção do reservatório sendo menor que atualmente, pôde-se observar na vistoria que o cobrimento de norma não foi seguido. Foi utilizado um cobrimento menor que ao da norma vigente da época de projeto. 
Tabela 2: Comparativo dos cobrimentos de concreto

\begin{tabular}{c|cc}
\hline \multirow{2}{*}{$\begin{array}{c}\text { Tipo de } \\
\text { Estrutura }\end{array}$} & \multicolumn{2}{|c}{ Cobrimento Nominal $(\mathbf{m m})$} \\
\cline { 2 - 3 } & 1980 & 2014 \\
\hline Laje & 20 & 25 \\
Viga & 25 & 30 \\
Pilar & 25 & 30 \\
\hline \multicolumn{3}{c}{ Fonte: Autores, 2019 }
\end{tabular}

Com base nas análises feitas, constou-se que a não obediência a norma NBR 6118 vigente na época de projeto e execução, quanto à comprimento de cobrimento mínimo, pode ter sido fundamental para o aparecimento das manifestações patológicas no reservatório elevado.

\section{CONCLUSÃO}

Os reservatórios elevados geralmente são construídas com concreto armado, cujo material é sujeito a apresentar manifestações patológicas oriundos de diversos fatores que vão desde a concepção de um projeto mal eleborado, até falhas na execução e uso de materiais inadequados. Dessa forma, o profissional responsável deve ter conhecimneto de todos os aspectos da obra e do ambiente que a envolve, e conscientizar os usuários da importância das manutenções de uma estrutura durante sua vida útil, prevenindo, assim, o aparecimento de problemas futuros.

Portanto, é possivel concluir que a falta de manutenção, a utilização de cobrimento discordantes com a norma, foram decisivas para o surgimento de manifestações patológicas no revervatório estudado, como as fissuras com corrosão de armaduras expostas.

Este trabalho fornece informações necessárias para iniciação do processo de intervenção no reservatório em questão, auxiliando na economia deste processo, já que as manutenções poderão ser pontuais nas manifestações patológicas.

\section{REFERÊNCIAS}

ALONSO, U. R. Previsão e Controle das Fundações. Edgard Blucher. São Paulo, 1991.

ANDRADE, T.; SILVA, A. J. C. Patologia das Estruturas. In: ISAIA, Geraldo Cechella (Ed.). Concreto: ensino, pesquisa e realizações. IBRACON. São Paulo, 2005.

ASSOCIAÇÃO BRASILEIRA DE NORMAS TÉCNICAS. NBR 15575-1: Edificações Habitacionais - Desempenho. Parte 1: Requisitos gerais. Rio de Janeiro, 2013.

ASSOCIAÇÃO BRASILEIRA DE NORMAS TÉCNICAS. NBR 6118: Projeto e execução de obras de concreto armado - Procedimento. Rio de Janeiro, 1980.

ASSOCIAÇÃO BRASILEIRA DE NORMAS TÉCNICAS. NBR 6118: Projeto de estruturas de concreto Procedimento. Rio de Janeiro, 2014.

ASSOCIAÇÃO BRASILEIRA DE NORMAS TÉCNICAS. NBR 6122: Projeto e execução de fundações. Rio de Janeiro, 2019.

CÁNOVAS, M. F. Patologia e Terapia do Concreto. 1 ed. São Paulo: PINI. 1988.

CAPUTO, H. P. Mecânica dos solos e suas aplicações. 6 ed. Rio de Janeiro: LTC, vol. 2, 2012.

CARRIÓ, Juan Monjo. Patologia de cerramientos y acabados arquitectonicos. Madrid, 2010 
GOMES, Rodrigo de Albergaria; SANTOS, Fabrício Fernandez da Silva. Estudo de Patologias em reservatório de concreto armado. In: Anais VIII SIMPAC, vol. 8. Viçosa, 2016.

GUIMARÃES, A. E. P. Indicações para projeto e execução de reservatórios cilíndricos em concreto armado. Dissertação de mestrado, Escola de Engenharia de São Carlos - USP, 1995.

MATTJE, A. Contribuição ao estudo da durabilidade de pontes em concreto do Sistema Rodoviário de Santa Catarina (Litoral e Vale do Itajaí). Dissertação de mestrado em Engenharia Civil. Universidade Federal de Santa Catarina. Florianópolis, 2003.

MilitiTSKY, J.; CONSOLI, N. C.; SCHINAID, F. Patologias das Fundações. $1^{\text {a }}$ ed. Editora Oficina de Textos. São Paulo, 2005.

PEREIRA, Eurico Ascenso. Patologia em reservatórios de água potável e sua correção. Lisboa, 2010. Disponível em: http://repositorio.ipl.pt//handle/10400.21/443. Acesso em: 10 de dezembro de 2019.

RIPPER, T; SOUZA, V. C. M. Patologia, recuperação e reforço de estruturas de concreto. 1 ed. Pini. São Paulo, 1998.

RODRIGUES, Aretusa Carvalho. Levantamento das principais manifestações patológicas em edificações residenciais de uma construtora de Porto Alegre. Dissertação para obtenção do titulo de Engenheiro Civil, Universidade Federal do Rio Grande do Sul. Porto Alegre, 2013.

SEVERINO, Antônio J. Metodologia do Trabalho Científico. 23 ed. rev, e atual. Sâo Paulo, 2007.

TORRES, A. S.; SILVA, V. M. B.; PALIGA, C. M. Análise das manifestações patológicas em reservatórios elevados na cidade de Pelotas/RS. IN: REEC, vol. 12. Pelotas, 2015.

TSUTIYA, Milton Tomoyuki. Abastecimento de Água. 4. ed. São Paulo: Departamento de Engenharia Hidráulica e Sanitária da Escola Politécnica da Universidade de São Paulo, 2006.

VERÇOZA, E. J. Patologia das Edificações. Editora Sagra. Porto Alegre, 1991. 